\title{
Torta de girassol em suplementos múltiplos para bovinos em pastejo no período seco do ano: parâmetros nutricionais
}

\section{Sunflower cake in multiple supplements for cattle grazing in the dry season: Nutritional characteristics}

\author{
Allan Cristian Mesacasa ${ }^{1}$; Joanis Tilemahos Zervoudakis ${ }^{2}$; Luciana Keiko \\ Hatamoto-Zervoudakis²; Luciano da Silva Cabral²; Joadil Gonçalves de Abreu²; \\ Renata Pereira da Silva-Marques ${ }^{3 *}$; Marcella Katherine Alonso ${ }^{4}$; \\ Rafael Gonçalves Ferrato da Silva ${ }^{4}$; Juliane Quenoizoré Soares ${ }^{5}$
}

\section{Resumo}

Objetivou-se avaliar o efeito dos níveis de inclusão da torta de girassol, como fonte proteica em substituição ao farelo de soja, em suplementos múltiplos para bovinos em pastejo durante período seco do ano sobre os parâmetros nutricionais. Foram utilizados cinco novilhos Nelore, não-castrados, com idade e peso médio inicial de 20 meses e $354,7 \mathrm{~kg}$, respectivamente; distribuídos em cinco piquetes de 0,25 ha cada, formados por Brachiaria brizantha cv Marandu. O experimento foi estruturado em quadrado latino $5 \times 5$, composto por cinco períodos experimentais de 15 dias cada e cinco animais. A estratégia adotada foi à inclusão da torta de girassol (TG) em níveis crescentes de 0,270, 406, $540 \mathrm{~g} /$ $\mathrm{kg}$ de suplemento, e suplemento composto apenas por mistura mineral fornecido a vontade no cocho (controle). Os suplementos foram formulados para serem isoproteicos (25\% PB) e fornecidos na quantidade de $1,5 \mathrm{~kg} / \mathrm{animal} / \mathrm{dia}$ de matéria natural. A massa de forragem e a disponibilidade de matéria seca pontecialmente digestível foram de 3.120 e $2.379 \mathrm{Kg}$ MS/ha respectivamente. Foi observado efeito $(\mathrm{P}<0,10)$ dos níveis de inclusão daTG em relação ao suplemento controle sobre os consumos de MS e PB. O CMSF foi numericamente superior nos animais suplementados ( $8,05 \mathrm{~kg}$ de MS/ dia) em relação os animais controle $(7,09 \mathrm{~kg}$ de MS/ dia). Não houve efeito dos suplementos sobre o $\mathrm{pH}$ ruminal $(\mathrm{P}>0,10)$. Houve diferença significativa para as concentrações de $\mathrm{N}_{-} \mathrm{NH}_{3}$ entre os animais que receberam apenas mistura mineral $(8,64 \mathrm{mg} / \mathrm{dL})$ e os bovinos suplementados com $0(12,61 \mathrm{mg} / \mathrm{dL})$ e $27 \%(11,79 \mathrm{mg} / \mathrm{dL})$ de inclusão de TG no tempo 4 horas após a suplementação. No entanto, a concentração de N-NH3, entre os animais suplementados, independente da inclusão de TG não foi significativa $(P>0,10)$, mas foi numericamente menor para os animais suplementados com 40,6 (10,81 mg/dL) e $54 \%(10,50 \mathrm{mg} /$ dL) de inclusão de torta de girassol. Conclui-se que a inclusão da torta de girassol na formulação dos suplementos não interferiu nos parâmetros nutricionais podendo substituir o farelo de soja em até $100 \%$ sem prejudicar o consumo dos animais, nesse nível de suplementação.

Palavras-chave: Co-produtos, forragem, novilhos

\footnotetext{
1 M.e em Ciência Animal, Universidade Federal do Mato Groso, UFMT, Cuiabá, MT. E-mail: allanmesacasa@hotmail.com

2 Profs. Drs., UFMT, Cuiabá, MT. E-mail: joanis@ufmt.br; lukeiko@yahoo.com.br; cabralls@ufmt.br; joadil@terra.com.br

3 Discente de Doutorado em Ciência Animal, UFMT, Cuiabá, MT. E-mail: renatinharps@hotmail.com

4 Médicos Veterinários, Cuiabá, MT. E-mail: marcellakatherine@hotmail.com; gfsrafael@hotmail.com

5 Discente de Mestrado em Ciência Animal, UFMT, Cuiabá, MT. E-mail: juliane_qs@hotmail.com

Autor para correspondência
} 


\begin{abstract}
The objective was to evaluate the effect of inclusion levels of sunflower cake as protein source to replace soybean meal in multiple supplements for cattle grazing during dry season on nutritional parameters. Five steers were used, Nellore, non-castrated, with age and average initial weights of 20 months and $354.7 \mathrm{~kg}$, respectively, divided into five paddocks of 0.25 ha each, consisting of Brachiaria brizantha cv. Marandu. The experiment was divided into 5 x 5 Latin square, composed of five experimental periods of 15 days each and five animals. The strategy adopted was the inclusion of sunflower cake in increasing levels of zero, 270, 406, $540 \mathrm{~g} / \mathrm{kg}$ supplement and mineral supplement composed only by the will provided in the trough (control). Supplements were formulated to be isonitrogenous $(25 \% \mathrm{CP})$ and provided the amount of $1.5 \mathrm{~kg}$ / animal / day of natural material. The forage mass and the availability of dry matter digestible pontecialmente were 3,120 and 2,379 $\mathrm{kg} \mathrm{DM} /$ ha respectively. Effect was observed $(\mathrm{P}<0.10)$ levels of inclusion of sunflower cake compared to the control of supplement DM intake and BP. The FDMI was numerically higher in the supplemented animals ( $8.05 \mathrm{~kg} \mathrm{DM} /$ day) over the control animals $(7.09 \mathrm{~kg} \mathrm{DM} /$ day). There was no effect of the supplements on ruminal $\mathrm{pH}(\mathrm{P}>$ 0.10). There was a significant difference in the concentrations of NH3-N between animals that received only mineral mixture $(8.64 \mathrm{mg} / \mathrm{dL})$ and cattle supplemented with $0(12.61 \mathrm{mg} / \mathrm{dL})$ and $27 \%(11.79$ $\mathrm{mg} / \mathrm{dL}$ ) of adding TG in time 4 hours after supplementation. However, the concentration of NH3-N, between supplemented animalsindependent of the inclusion of TG was not significant ( $P>0.10)$, but was numerically lower for animals supplemented with 40.6 (10.81 mg / dL ) and 54\% (10.50 mg / dL) inclusion of sunflower cake. We conclude that the inclusion of sunflower cake in the formulation of the supplements did not interfere with nutritional parameters can replace soybean meal in up to $100 \%$ without affect consumption of animals, this level of supplementation.
\end{abstract}

Key words: Formulation, feed, steers

\section{Introdução}

Nos sistemas de produção de bovinos baseados exclusivamente na utilização da forragem como fonte de nutrientes, o desempenho animal pode ser inferior ao determinado geneticamente e/ou desejado para satisfazer os objetivos da produção, além disso, os animais podem apresentar deficiências múltiplas de nutrientes, especialmente durante o período seco do ano, no qual ocorre a estação de menor produtividade das plantas ocasionada pelo déficit hídrico (COUTINHO FILHO; JUSTO; PERES, 2005). Para assegurar melhoria na utilização de forragens de baixa qualidade, é fundamental suprir as exigências de nutrientes dos microrganismos ruminais, ampliando sua taxa de crescimento e a extração de energia a partir dos carboidratos da forragem (PAULINO et al., 2004). A suplementação é uma prática adotada em alguns sistemas de produção de bovinos com o objetivo de fornecer o aporte de nutrientes necessários a microbiota ruminal para o melhor consumo.
Ao incluir a suplementação no manejo nutricional dos animais, o consumo alimentar é passo fundamental na formulação da dieta, pois segundo Mendes et al. (2005), características físicas e/ou químicas do alimento podem interferir de maneira positiva ou negativa no consumo de matéria seca pelo animal.

A utilização dos co-produtos do girassol na dieta de bovinos tem crescido nos últimos anos, devido principalmente ao aumento na área de cultivo dessa cultura, que se destaca no cenário nacional como promissora. A torta de girassol que resulta do esmagamento mecânico do grão com casca, sem o cozimento ou utilização de solvente, por não utilizar temperaturas elevadas segundo De Souza (2008) tem menor problema quanto à limitação em lisina. Além disso, a torta por apresentar maior teor de extrato etéreo (EE) em relação ao farelo, contribui para menor emissão de metano por ruminantes, pois segundo Abdalla et al. (2008) estudos realizados na Austrália comprovaram que para cada $1 \%$ de acréscimo de gordura na dieta de ruminantes, 
pode se reduzir até $6 \%$ na quantidade de metano produzido por kg de matéria seca consumida.

Porém em função das diversas maneiras de extração do óleo, o resultado do uso da torta de girassol na alimentação de ruminantes pode variar bastante em termos de composição, digestibilidade, consumo e principalmente desempenho animal (OLIVEIRA; CÁCERES, 2005).

Desta maneira objetivou-se avaliar o uso da torta de girassol em níveis crescentes na formulação de suplementos múltiplos, sobre algumas características nutricionais de bovinos mantidos sob pastejo na época da seca.

\section{Material e Métodos}

O experimento foi conduzido no setor de Bovinocultura de Corte, da Fazenda Experimental da Faculdade de Agronomia, Medicina Veterinária e Zootecnia - FAMEVZ da Universidade Federal de Mato Grosso - UFMT, no período da seca, entre os meses de maio a agosto. O clima da região é do tipo Aw de acordo com a classificação Köppen, ou seja, clima tropical, megatérmico, com inverno seco e chuvas no verão (Tabela 1 ).

Tabela 1. Valores médios das temperaturas máximas e mínimas, umidade relativa do ar e precipitação pluviométrica, coletadas durante o período experimental.

\begin{tabular}{cccc}
\hline \multirow{2}{*}{ Mês } & \multicolumn{2}{c}{ Temperatura Média $\left({ }^{\circ} \mathrm{C}\right)$} & $\begin{array}{c}\text { Precipitação } \\
(\text { MM })\end{array}$ \\
\cline { 2 - 4 } & \multicolumn{3}{c}{ Máxima Mínima } \\
Maio & 30,2 & 17,4 & 67,8 \\
Junho & 32,8 & 16,0 & 0,0 \\
Julho & 30,5 & 14,5 & 8,5 \\
Agosto & 34,5 & 14,5 & 0,0 \\
\hline Total & \multicolumn{2}{c}{76,30} \\
\hline
\end{tabular}

Fonte: Estação Agrometeorológica Padre Ricardo Remetter - Fazenda Experimental UFMT.

Foram utilizados cinco novilhos, Nelore, nãocastrados, com idade e pesos médios iniciais de 20 meses e $354,7 \pm 11,0 \mathrm{~kg}$, respectivamente, destinados individualmente a cinco piquetes (vedados aproximadamente 40 dias antes do início do experimento) de 0,24 ha cada, formados com gramínea Brachiaria brizantha cv. Marandu, contendo bebedouro e comedouro coberto. Paralelamente aos piquetes, situava-se o curral de manejo, no qual foram realizadas as coletas nos animais. Ao início do experimento, todos os animais foram submetidos ao controle de endo e ectoparasitas.

O experimento foi conduzido em delineamento em quadrado latino $5 \times 5$, com cinco animais e cinco suplementos. Cada período experimental teve duração de 15, totalizando 75 dias. Os animais foram rotacionados entre os piquetes a cada início de período experimental.

Foram avaliados suplemento mineral (ad libitum) e suplementos múltiplos com inclusão da torta de girassol em níveis crescentes: $0 ; 270 ; 406$ e 540 $\mathrm{g} / \mathrm{kg}$; baseado na matéria natural, com objetivo de substituir a proteína do farelo de soja em $0,50,75$, e $100 \%$ respectivamente. Os suplementos (Tabela 2) foram formulados para serem isoproteicos, $(25 \%$ de PB com base na matéria seca), fornecidos na quantidade de 1,5 kg/animal/dia na matéria natural, de forma a atender as exigências nutricionais de bovinos Nelore, não castrados com peso corporal de $350 \mathrm{~kg}$ e ganho de $450 \mathrm{~g} / \mathrm{dia}$ (VALADARES FILHO; PAULINO; MAGALHÃES, 2006). 
Os suplementos foram fornecidos diariamente às 10:00h para evitar interferência no comportamento de pastejo dos animais (ADAMS, 1985). Os animais foram pesados no início e no final de cada período experimental sem jejum prévio, sempre pela manhã.
No primeiro dia de cada período experimental foi realizada a coleta de pasto para determinação da massa de forragem/ha, através do corte ao nível do solo de cinco áreas delimitadas por um quadrado metálico de 0,5 x 0,5 m, escolhidos aleatoriamente em cada piquete experimental (McMENIMAN, 1997).

Tabela 2. Composição $(\mathrm{g} / \mathrm{Kg})$ dos suplementos, com base na matéria natural.

\begin{tabular}{|c|c|c|c|c|c|}
\hline \multirow[b]{2}{*}{ Ingredientes } & \multicolumn{4}{|c|}{ Inclusão da torta de girassol ( $\mathrm{g} / \mathrm{kg}$ suplemento) } & \multirow{2}{*}{$\mathrm{SM}^{3}$} \\
\hline & $0 \mathrm{TG}^{1}$ & $27 \mathrm{TG}^{1}$ & $40,6 \mathrm{TG}^{1}$ & $54 \mathrm{TG}^{1}$ & \\
\hline Torta de girassol & ---- & 270,0 & 406,0 & 540,0 & ------ \\
\hline Farelo de soja & 265,0 & 132,5 & 66,0 & ---- & ------ \\
\hline Milho & 655,0 & 512,5 & 440,0 & 370,0 & ----- \\
\hline Ureia $^{2}$ & 30,0 & 35,0 & 38,0 & 40,0 & ----- \\
\hline Mistura Mineral ${ }^{3}$ & 50,0 & 50,0 & 50,0 & 50,0 & 100,0 \\
\hline Total $(\mathrm{g} / \mathrm{Kg})$ & 1000,0 & 1000,0 & 1000,0 & 1000,0 & 1000,0 \\
\hline
\end{tabular}

1: 0TG, 27TG, 40,6TG, 54TG: inclusão em g/Kg de torta de girassol com base na matéria natural.

2: ureia: sulfato de amônia $(9: 1)$

${ }^{3} \mathrm{SM}$ - Suplemento mineral comercial: Níveis de garantia: cálcio $198 \mathrm{~g}$; fósforo $87 \mathrm{~g}$; sódio 97,6g; magnésio 5,1g; enxofre 12g; iodo $17,7 \mathrm{mg}$; ferro $280 \mathrm{mg}$; selênio $18 \mathrm{mg}$; cobalto $80 \mathrm{mg}$; manganês $527 \mathrm{mg}$; flúor $870 \mathrm{mg}$; cobre $1.250 \mathrm{mg}$ e zinco $3.500 \mathrm{mg} . \%$

Fonte: Elaboração dos autores.

Após a pesagem, as amostras foram homogeneizadas por piquete e por período. Das amostras obtidas, uma subamostra foi seca em estufa de ventilação forçada a $65{ }^{\circ} \mathrm{C}$, moída em moinho tipo Willey (peneira de $1,0 \mathrm{~mm}$ ), enquanto a outra foi utilizada para a separação dos componentes botânicos das plantas: lâmina foliar verde (LFV), pseudocolmo verde (PCV), lâmina foliar seca (LFS) e pseudocolmo seco (PCS).

A coleta da forragem ingerida pelos animais foi realizada por intermédio de simulação manual do pastejo, sendo coletada no primeiro dia de cada período experimental. As amostras foram imediatamente pesadas após a coleta e congeladas a $-20^{\circ} \mathrm{C}$ sendo posteriormente descongeladas e secas em estufa de ventilação forçada a $65^{\circ} \mathrm{C}$, moída em moinho tipo Willey (com peneira com orifícios de 1,0 mm de diâmetro), para posterior analises químico-bromatológicas.

Amostras dos ingredientes e dos suplementos foram coletadas em todas as batidas (mistura) e congeladas a $-20^{\circ} \mathrm{C}$, sendo posteriormente, após o término do experimento de campo, descongeladas, homogeneizadas, e retiradas alíquotas para que fossem realizadas as análises laboratoriais.

Das amostras destinadas à estimativa de massa de forragem (MF), foi determinado o resíduo insolúvel em detergente neutro avaliado após incubação in situ das amostras por 244 horas (FDNi) (CASALI et al., 2008), para cálculo do percentual de matéria seca potencialmente digestível (MSpD) disponível aos animais. Esse resultado foi estimado por intermédio da seguinte equação:

$\operatorname{MSpD}(\%$ da MS $)=0,98 \times(100-$ FDN $)+$ (FDN - FDNi);

Em que: $0,98=$ coeficiente de digestibilidade verdadeiro do conteúdo celular;

Para estimativa da excreção de MS fecal, foram fornecidas $10 \mathrm{~g}$ de oxido de cromo diariamente, no qual foi acondicionado em cartuchos de papel e introduzido diretamente no esôfago em dose 
unica às $11: 00 \mathrm{~h}$, do $5^{\circ}$ ao $12^{\circ}$ dia de cada período experimental. Posteriormente realizaram-se três coletas de amostra de fezes (aproximadamente $300 \mathrm{~g}$ ), por via retal; coletadas às $16: 00 \mathrm{~h}$ no $11^{\circ}$ dia, às $12: 00 \mathrm{~h}$ no $12^{\circ}$ dia, e às $8: 00 \mathrm{~h}$ no $13^{\circ}$ dia. Imediatamente após as coletas, as amostras de fezes foram acondicionadas em sacos plástico, identificadas e congeladas $\mathrm{a}-10^{\circ} \mathrm{C}$.

Posteriormente as amostras de fezes foram présecadas em estufa de ventilação forçada $\left(56^{\circ} \mathrm{C}\right)$, por 72 horas; e moídas em moinho de facas com peneira de orifícios de $1 \mathrm{~mm}$ de diâmetro. Após o procedimento de secagem e moagem, foi realizada a composta de animal/período, e armazenadas em sacos plásticos devidamente identificados.

A estimativa da excreção fecal de MS (EFMS) foi feita considerando-se a razão entre a quantidade de indicador fornecido e sua concentração nas fezes:

EFMS $(\mathrm{Kg} /$ dia $)=$ [quantidade fornecida do indicador $(10 \mathrm{~g} / \mathrm{dia}) /$ concentração do indicador nas fezes]x100.

Adotou-se a FDNi como indicador interno para estimar o consumo voluntário de MS. As amostras de fezes, pastejo simulado, ingredientes e suplementos foram incubadas por 244 horas em bovino com cânula ruminal para estimar o teor de FDNi das amostras experimentais.

Para estimativa do consumo voluntário de MS dos animais foi utilizada a equação proposta por Detmann et al. (2001):

CMS $(\mathrm{Kg} /$ dia $)=\{[($ EFMSxFDNiF $)-$ IFDNiS $] /$ CFDNiF\} + CMSS, onde:

CMS $(\mathrm{kg} / \mathrm{dia})=$ consumo de matéria seca; EFMS = excreção fecal de MS (kg/dia); CFDNiF = concentração de FDNi nas fezes $(\mathrm{kg} / \mathrm{kg})$; IFDNIS = Ingestão de FDNi via suplemento ( $\mathrm{kg} / \mathrm{dia}) ; \mathrm{FDNiF}=$ concentração de FDNi na forragem $(\mathrm{kg} / \mathrm{kg})$ e CMSS = consumo de matéria seca de suplemento $(\mathrm{kg} / \mathrm{dia})$.

No $14^{\circ}$ dia, quatro horas após o fornecimento do suplemento, foi realizado a coleta de sangue e urina dos animais para determinação de ureia e creatinina.
O sangue foi centrifugado a $4000 \mathrm{rpm}$, durante 15 minutos para a extração do soro, que foi congelado a $-20^{\circ} \mathrm{C}$ para posterior quantificação dos teores de creatinina e ureia (VALADARES et al., 1999).

As coletas de urina, na forma de amostra "spot", foram realizadas no momento da micção espontânea dos animais, sendo armazenadas duas alíquotas. A primeira, destinada à determinação da concentração de ureia e creatinina que se constituiu de $10 \mathrm{~mL}$ de urina e $40 \mathrm{~mL}$ de ácido sulfúrico 0,036 N. A segunda alíquota foi congelada contendo cerca de $50 \mathrm{ml}$ de urina pura.

A concentração de creatinina na amostra urinária "spot" foi estimada por intermédio de kit comercial (No. 555-A; Sigma Chem. Co., St. Louis, MO). O volume total urinário foi avaliado por intermédio da relação entre concentração de creatinina na urina e sua excreção por unidade de peso corporal, adotando-se como padrão o valor de $27,36 \mathrm{mg} / \mathrm{kg}$ PV (RENNÓ et al., 2000). O balanço de compostos nitrogenados foi obtido pela diferença entre o total de nitrogênio ingerido e o excretado na urina e fezes.

Para determinação do $\mathrm{pH}$ e concentração de nitrogênio amoniacal $\left(\mathrm{N}-\mathrm{NH}_{3}\right)$ no líquido ruminal, as amostras foram coletadas através de sonda orogástrica, no $15^{\circ}$ dia do período experimental, imediatamente antes da suplementação e 4 horas após o fornecimento do suplemento (09:30 e 14:00 $h$, respectivamente). As análises de $\mathrm{pH}$ foram feitas imediatamente após a coleta por intermédio de peagâmetro digital. Para a determinação de amônia, separou-se uma alíquota de $50 \mathrm{~mL}$ de líquido ruminal que foi fixada com $1 \mathrm{~mL}$ de ácido sulfúrico (H2SO4) 1:1, sendo acondicionada em recipiente de plástico com tampa, identificada e congelada a $20^{\circ} \mathrm{C}$, para posteriores análises laboratoriais.

Para relacionar o consumo ao peso corporal (PC) dos animais, foi utilizado como referência o peso médio no período, estimado pela média entre o valor inicial e final de cada período experimental.

Nas amostras de fezes, forragem obtida por simulação manual do pastejo animal, ingredientes 
e suplementos foram realizadas as determinações da MS, matéria orgânica (MO), proteína bruta (PB), fibra em detergente neutro (FDN), fibra em detergente ácido (FDA), fibra em detergente neutro corrigida para cinza e proteína (FDNcp), extrato etéreo (EE) e cinzas (CZ). A determinação do nitrogênio insolúvel em detergente neutro (NIDN) foi realizada de acordo com descrições de Silva e Queiroz (2002).

A determinação da FDN dos ingredientes e suplementos foram realizados de acordo com recomendado por Van Soest, Robertson e Lewis (1991) para alimentos com alto teor de amido sendo as amostras tratadas com uma solução de ureia a $8 \mathrm{M}$ e enzima alfa amilase, sendo as análises posteriores, em sequencial, feitas de acordo com Silva e Queiroz (2002).

A quantificação dos carboidratos não fibrosos (CNF) dos suplementos foi realizada de acordo com adaptação de Hall (2000) em virtude da inclusão de ureia na composição dos suplementos, sendo:

$\mathrm{CNF}=100-[(\% \mathrm{~PB}-\% \mathrm{~PB}$ da ureia $+\%$ ureia $)$ $+\mathrm{FDNcp}+\% \mathrm{EE}+\%$ cinzas $]$

Onde: $\mathrm{FDNcp}=$ fibra em detergente neutro corrigida para cinza e proteína.

Os teores de carboidratos totais dos alimentos (CT) foram calculados segundo Sniffen et al. (1992):

$$
\mathrm{CT}=100-(\% \mathrm{~PB}+\% \mathrm{EE}+\% \text { Cinzas })
$$

Os Carboidratos não fibrosos (CNF) da forragem foram calculados pela diferença entre os CT e FDNcp.

Os dados coletados foram submetidos a análise de variância e teste de medias de student Newmann Kells adotando-se 10\% como nível de significância.

\section{Resultados e Discussão}

A massa de forragem (MF) média foi de $3120 \mathrm{~kg}$ MS/ha (Figura 1), estando sempre acima dos valores considerados críticos por Santos et al. (2004), que é de $2000 \mathrm{~kg} \mathrm{MS} /$ ha. Portanto a MF não interferiu negativamente no desempenho dos animais e pode ser atribuída ao processo de diferimento realizado por 40 dias antes do início do experimento. Porém a DMSpD teve queda gradativa ao longo dos períodos situando-se em torno de $82,3 \%$ no primeiro período e $73,27 \%$ no quinto período, sendo explicado pelas alterações na estrutura do dossel forrageiro como a elevação nas proporções de pseudocolmo seco de $10 \%$ para $21,23 \%$ e queda de lâmina foliar verde de $32,4 \%$ para $21,21 \%$ no último período experimental.

As alterações na estrutura do dossel forrageiro ao longo do tempo promoveram queda na qualidade da forragem, devido às elevadas taxas de amadurecimento da gramínea, que para Cabral et al. (2008), resulta no aumento dos teores dos constituintes fibrosos, notadamente tecidos lignificados, baixo conteúdo celular e compostos nitrogenados, podendo ser verificado de forma mais perceptível do primeiro para o segundo período principalmente pela elevação no teor de FDNi e NIDN (Tabela 3), e diminuição no teor proteico da gramínea (em torno de 4,30\% PB), abaixo dos 7\% considerado pelo NRC (2001) como limitante ao desenvolvimento dos microrganismos no rúmen.

O teor médio de FDN da forragem encontrado no presente estudo foi de $73,76 \%$, valor semelhante ao encontrado por Gerdes etal. (2000) de 72,70\%. O teor de FDA apresentou aumento de aproximadamente $21 \%$ até o término do experimento, tendo média de $36,47 \%$ da MS, considerado intermediário, pois gramíneas com teor de FDA abaixo de $30 \%$ possuem consumo elevado, enquanto que aquelas com teores acima de $40 \%$ acarretam a menor ingestão pelos ruminantes (BERCHIELLI; PIRES; OLIVEIRA, 2006).

Os suplementos foram previamente formulados para conter $25 \% \mathrm{~PB}$, e revelaram em média, $27,1 \%$ $26,9 \% ; 27,72 \%$ e $28,25 \%$ para os suplementos 0 TG, 27 TG, 40,6 TG e 54 TG respectivamente (Tabela 4). 
Figura 1. Valores médios de massa de forragem (MF), disponibilidades de MS potencialmente digestível (MSpD), MS de lâmina foliar verde (MLFV), MS de lâmina foliar seca (MLFS), MS de pseudocolmo verde (MPCV) e MS de pseudocolmo seco (MPCS) de Brachiaria brizantha cv. Marandu nos períodos experimentais.

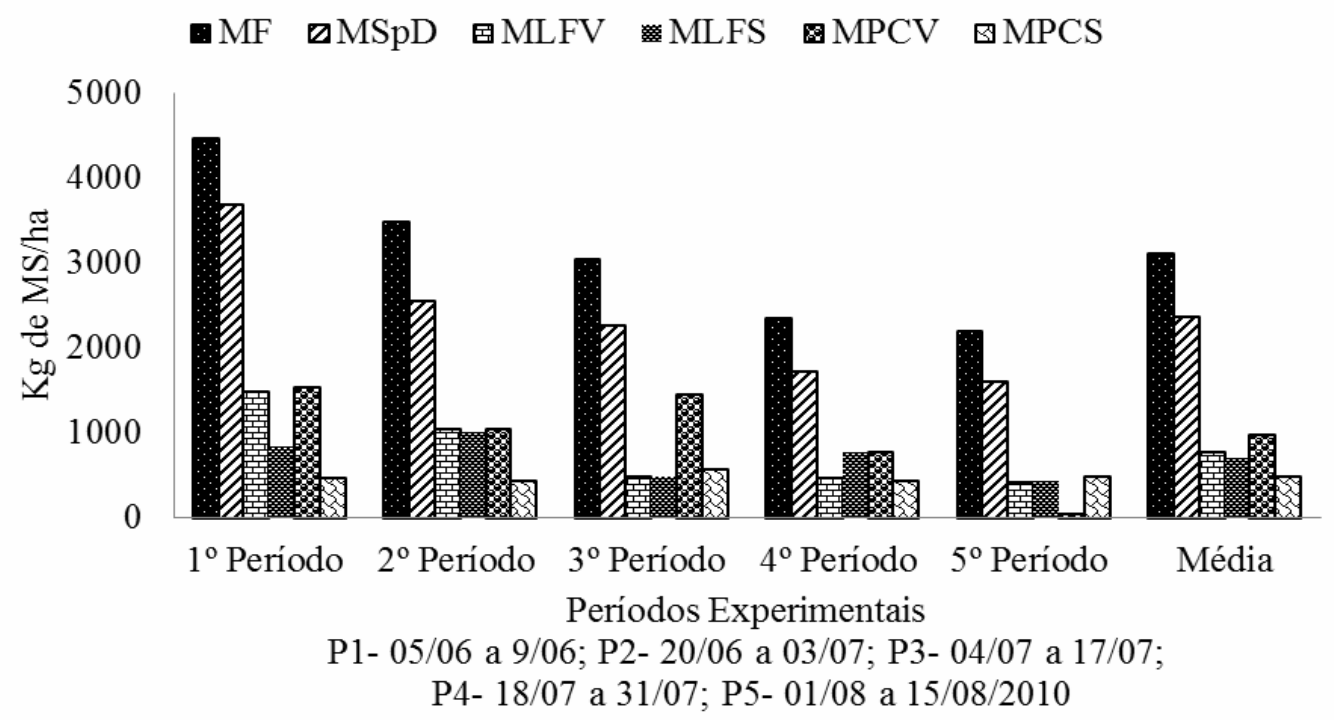

Fonte: Elaboração dos autores.

Tabela 3. Composição nutricional da forragem durante os períodos experimentais.

\begin{tabular}{ccccccc}
\hline Item & $1^{\circ}$ Período & $2^{\circ}$ Período & $3^{\circ}$ Período & $4^{\circ}$ Período & $5^{\circ}$ Período & Média \\
\hline MS (\%) & 31,44 & 37,16 & 37,95 & 40,90 & 39,93 & 37,47 \\
MO $^{1}$ & 91,15 & 91,03 & 91,12 & 91,5 & 92,16 & 91,84 \\
PB $^{1}$ & 7,59 & 4,22 & 4,43 & 4,09 & 4,59 & 4,98 \\
CZ $^{1}$ & 8,85 & 8,97 & 8,88 & 8,50 & 7,84 & 8,60 \\
FDN $^{1}$ & 69,61 & 74,44 & 72,95 & 75,07 & 76,75 & 73,76 \\
FDNcp $^{1}$ & 65,03 & 68,44 & 67,98 & 69,6 & 72,54 & 68,71 \\
FDNi $^{1}$ & 16,83 & 25,99 & 24,98 & 26,07 & 26,24 & 24,02 \\
FDA $^{1}$ & 30,26 & 37,89 & 38,70 & 37,23 & 38,30 & 36,47 \\
NIDN $^{2}$ & 17,9 & 23,45 & 19,63 & 27,38 & 27,66 & 23,20 \\
\hline
\end{tabular}

$1 \%$ da matéria seca; 2 \% do N total; MS - Matéria seca; MO - Matéria orgânica; PB - Proteína bruta; CZ - Cinzas; FDN - Fibra em detergente neutro; FDNcp - Fibra em detergente neutro corrigida para cinzas e proteína; FDNi - Fibra em detergente neutro indisponível; FDA - Fibra em detergente ácido; NIDN - Nitrogênio indisponível em detergente neutro.

Fonte: Elaboração dos autores. 
Tabela 4. Composição nutricional dos ingredientes e suplementos com base na matéria seca.

\begin{tabular}{|c|c|c|c|c|c|c|c|}
\hline \multirow[t]{2}{*}{ Itens } & \multicolumn{3}{|c|}{ Ingredientes } & \multicolumn{4}{|c|}{ Inclusão da torta de girassol (g/kg suplemento) } \\
\hline & Milho & F. soja & T. girassol & 0TG & $27 \mathrm{TG}$ & $40,6 \mathrm{TG}$ & 54TG \\
\hline MS (\%) & 88,40 & 88,69 & 95,34 & 89,39 & 91,09 & 91,70 & 92,77 \\
\hline $\mathrm{MO}^{1}$ & 98,49 & 93,12 & 94,16 & 92,04 & 92,09 & 91,82 & 91,63 \\
\hline $\mathrm{PB}^{1}$ & 8,35 & 51,06 & 25,33 & 27,10 & 26,90 & 27,72 & 28,25 \\
\hline $\mathrm{EE}^{1}$ & 4,45 & 1,46 & 16,54 & 2,85 & 7,57 & 9,08 & 11,32 \\
\hline $\mathrm{CZ}^{1}$ & 1,51 & 6,88 & 5,84 & 7,96 & 7,91 & 8,18 & 8,37 \\
\hline $\mathrm{FDN}^{1}$ & 19,04 & 21,35 & 48,53 & 25,96 & 34,80 & 38,58 & 41,72 \\
\hline FDNcp $^{1}$ & 15,60 & 17,26 & 40,32 & 18,31 & 25,51 & 28,65 & 29,59 \\
\hline $\mathrm{FDNi}^{1}$ & 0,78 & 2,35 & 22,75 & 2,07 & 7,75 & 9,21 & 12,75 \\
\hline $\mathrm{FDA}^{1}$ & 4,79 & 14,25 & 35,42 & 9,98 & 16,26 & 21,32 & 24,62 \\
\hline $\mathrm{CT}^{1}$ & 85,69 & 40,60 & 52,29 & 62,09 & 57,62 & 55,02 & 52,06 \\
\hline $\mathrm{CNF}^{1}$ & 70,09 & 23,34 & 11,97 & 48,66 & 34,72 & 39,57 & 26,43 \\
\hline NIDN $^{2}$ & 22,57 & 12,80 & 34,00 & 18,2 & 19,44 & 21,20 & 21,45 \\
\hline
\end{tabular}

1 \% da matéria seca; ${ }^{2}$ \% do N total; MS - Matéria seca; MO - Matéria orgânica; PB - Proteína bruta; EE - Extrato etéreo; CZ Cinzas; FDN - Fibra em detergente neutro; FDNcp - Fibra em detergente neutro corrigida para cinzas e proteína; FDNi - Fibra em detergente neutro indisponível; FDA - Fibra em detergente ácido; CT - Carboidratos totais; CNF - Carboidratos não-fibrosos; NIDN - Nitrogênio indisponível em detergente neutro.

Fonte: Elaboração dos autores.

A inclusão da torta de girassol reduziu a baixo nível de fornecimento dos suplementos $(0,4 \%$ qualidade do suplemento, ou seja, promoveu PC), o consumo de MS dos animais suplementados acréscimo no teor de FDNi e NIDN, podendo não diferiu estatisticamente (tabela 5). prejudicar o consumo de matéria seca. Porém pelo

Tabela 5. Valores médios de consumos de matéria seca (CMS), matéria seca de forragem (CMSF), proteína bruta (CPB), fibra em detergente neutro (CFDN) de novilhos suplementados com mistura mineral (SM) ou suplementos com níveis crescentes de torta de girassol.

\begin{tabular}{|c|c|c|c|c|c|c|}
\hline \multirow[b]{2}{*}{ Item } & \multicolumn{4}{|c|}{ Inclusão da torta de girassol (g/kg suplemento) } & \multirow{2}{*}{$\mathrm{SM}^{1}$} & \multirow{2}{*}{ CV $(\%)$} \\
\hline & $0 \mathrm{TG}$ & $27 \mathrm{TG}$ & $40,6 \mathrm{TG}$ & $54 \mathrm{TG}$ & & \\
\hline & & \multicolumn{5}{|c|}{$\mathrm{Kg} / \mathrm{dia}$} \\
\hline $\mathrm{CMST}^{2}$ & $9,20^{\mathrm{a}}$ & $9,86^{\mathrm{a}}$ & $9,54^{\mathrm{a}}$ & $9,93^{\mathrm{a}}$ & $7,09^{b}$ & 19,46 \\
\hline $\mathrm{CMSF}^{3}$ & 7,70 & 8,49 & 8,18 & 7,83 & 7,09 & 15,91 \\
\hline $\mathrm{CPB}^{4}$ & $0,76^{\mathrm{a}}$ & $0,79^{\mathrm{a}}$ & $0,77^{\mathrm{a}}$ & $0,78^{\mathrm{a}}$ & $0,36^{\mathrm{b}}$ & 31,18 \\
\hline $\mathrm{CFDN}^{5}$ & $6,02^{\mathrm{ab}}$ & $6,79^{\mathrm{a}}$ & $6,58^{\mathrm{a}}$ & $6,35^{\mathrm{ab}}$ & $5,22^{\mathrm{b}}$ & 16,68 \\
\hline & & \multicolumn{5}{|c|}{$\% \mathrm{PV}$} \\
\hline CMST & $2,33^{\mathrm{a}}$ & $2,53^{\mathrm{a}}$ & $2,15^{\mathrm{ab}}$ & $2,36^{\mathrm{a}}$ & $1,85^{\mathrm{b}}$ & 16,58 \\
\hline CMSF & 1,98 & 2,18 & 2,09 & 2,0 & 1,85 & 15,14 \\
\hline $\mathrm{CPB}$ & 0,19 & 0,20 & 0,20 & 0,20 & 0,09 & 32,28 \\
\hline CFDN & $1,54^{\mathrm{ab}}$ & $1,72^{\mathrm{a}}$ & $1,68^{\mathrm{ab}}$ & $1,62^{\mathrm{ab}}$ & $1,36^{\mathrm{b}}$ & 15,15 \\
\hline
\end{tabular}

Médias com letras diferentes sobrescrita na linha diferem entre si $(\mathrm{P}<0,10)$ pelo teste $\mathrm{SNK}$

${ }^{1} \mathrm{SM}$ - Suplemento mineral comercial; $2,3,4,5$ : Consumo de matéria seca total, matéria seca de forragem, proteína bruta e fibra em detergente neutro, respectivamente.

Fonte: Elaboração dos autores. 
Com a adequada formulação dos suplementos, o consumo de $\mathrm{PB}$ pelos bovinos não diferiu estatisticamente $(\mathrm{P}>0,10)$ entre os animais que receberam suplementos com inclusão da torta de girassol. No entanto, os animais suplementados apresentaram consumo de $\mathrm{PB}$ superior $(\mathrm{P}<0,10)$ aos animais controle (sal mineral). Além disso, foi observada diferença estatística referente ao CMST $(\mathrm{P}<0,10)$, no qual o grupo que recebeu apenas mistura mineral como fonte suplementar, apresentou consumo inferior (26\%) diante dos grupos que receberam suplementos múltiplos, e o CMSF foi numericamente superior nos animais suplementados $(8,05 \mathrm{~kg}$ de MS/dia) em relação aos animais controle $(7,09 \mathrm{~kg}$ de MS/dia), mostrando que a estratégia adotada promoveu maior aporte de nutrientes e não afetou negativamente o consumo de forragem, correspondendo ao princípio fundamental da suplementação a pasto, em que o suplemento proteico estimula o consumo sem promover efeito substitutivo.
Em contrapartida, Domingues et al. (2010), observaram que a inclusão da torta de girassol em substituição ao farelo de algodão em bovinos confinados levou à queda de ingestão de matéria seca. A diferença observada por Domingues et al. (2010) pode ser atribuída ao maior consumo de torta de girassol, o qual atingiu aproximadamente 2,4 $\mathrm{kg} / \mathrm{animal} / \mathrm{dia}$ de torta na dieta de maior inclusão, enquanto que no presente estudo o consumo máximo de torta de girassol foi de $609 \mathrm{~g} / \mathrm{animal} / \mathrm{dia}$.

Houve diferença estatística significativa $(\mathrm{P}<0,10)$, para as concentrações de N-NH3 entre os animais que receberam apenas mistura mineral e os bovinos suplementados com 0 e $27 \%$ de inclusão de torta de girassol no tempo 4 horas após a suplementação (Tabela 6), o que pode ser explicado pelo maior consumo de $\mathrm{PB}$, pois de acordo com DelCurto et al. (1990), a suplementação proteica tem sido associada com a elevação na concentração de N-NH3 no ambiente ruminal, possibilitando melhor degradação da forragem e consequentemente maior consumo.

Tabela 6. Valores médios de pH e concentração de nitrogênio amoniacal (N-NH3) (mg/dL), no liquido ruminal de novilhos nelores suplementados com mistura mineral (SM)ou suplementos com níveis crescentes de torta de girassol no período das secas, nos diferentes tempos de amostragem: antes da alimentação e 4 horas após alimentação.

\begin{tabular}{|c|c|c|c|c|c|c|c|}
\hline \multirow[b]{2}{*}{ Item } & \multirow[b]{2}{*}{ Tempo } & \multicolumn{4}{|c|}{ Inclusão da torta de girassol (g/kg suplemento) } & \multirow{2}{*}{$\mathrm{SM}^{1}$} & \multirow{2}{*}{$\mathrm{CV}(\%)$} \\
\hline & & $0 \mathrm{TG}$ & $27 \mathrm{TG}$ & $40,6 \mathrm{TG}$ & $54 \mathrm{TG}$ & & \\
\hline $\mathrm{pH}$ & 0 & 6,64 & 6,68 & 6,77 & 6,70 & 6,82 & 3,19 \\
\hline \multirow{3}{*}{$\mathrm{N}-\mathrm{NH}_{3}$} & 4 & $6,52^{\mathrm{a}}$ & $6,56^{\mathrm{a}}$ & $6,56^{\mathrm{a}}$ & $6,60^{\mathrm{a}}$ & $6,62^{\mathrm{a}}$ & 2,91 \\
\hline & 0 & 7,38 & 6,72 & 7,13 & 6,13 & 5,30 & 40,09 \\
\hline & 4 & $12,61^{\mathrm{a}}$ & $11,79^{\mathrm{a}}$ & $10,81^{\mathrm{ab}}$ & $10,50^{\mathrm{ab}}$ & $8,64^{\mathrm{b}}$ & 19,21 \\
\hline
\end{tabular}

Médias com letras diferentes sobrescrita na linha diferem entre si $(\mathrm{P}<0,10)$ pelo teste SNK.

${ }^{1}$ Suplemento mineral comercial.

Fonte: Elaboração dos autores.

No entanto, a concentração de N-NH3, no tempo 4 horas, entre os animais suplementados, independente da inclusão de TG não foi significativa $(\mathrm{P}>0,10)$, mas foi numericamente menor para os animais suplementados com 40,6 e $54 \%$ de inclusão de torta de girassol, ou seja, o aumento no fornecimento da torta de girassol promoveu decréscimo na concentração de nitrogênio amoniacal ruminal. Considerando que com a inclusão da torta de girassol não houve diferença sobre o consumo estimado de PB, essa diferença pode ser explicada pela maior fração indigestível da torta de girassol frente ao farelo de soja, pois de acordo com Beran et al. (2005), em estudo avaliando a degradabilidade da 
PB de diversos alimentos usados na suplementação de bovinos, observaram que a fração indigestível da PB do farelo de soja foi de $0,48 \%$ enquanto que a fração indigestível (C) da torta de girassol chegou a $3,92 \%$, o que torna mais lenta a degradabilidade desse alimento. Corroborando com o observado por Beran et al. (2005); o elevado teor de NIDN encontrado na torta de girassol do presente estudo contribuiu negativamente na qualidade dos suplementos com maior inclusão da torta de girassol, podendo ter promovido menor concentração de N-NH3 no tempo 4 horas.

Os valores observados de N-NH3, quando os animais receberam apenas mistura mineral no tempo 4 horas $(8,64 \mathrm{mg} / \mathrm{dL})$, foram superiores ao observado por Goes et al. (2005) de 7,57 mg/dL no período das secas, e todos os valores foram superiores ao considerado pelo NRC (2001) como prejudicial ao crescimento microbiano $(<5 \mathrm{mg} / \mathrm{dL})$; sendo que nos animais que receberam os suplementos proteicos, a concentração de N-NH3 manteve-se dentro da faixa ideal considerada por Leng. (1990) para condições tropicais (10 a $20 \mathrm{mg} / \mathrm{dL}$ ).

Não houve diferença estatística $(\mathrm{P}>0,10)$, para o valor de $\mathrm{pH}$ que permaneceu em torno de 6,72 no tempo 0 horas, e 6,57 no tempo 4 horas após a suplementação, não prejudicando a microbiota ruminal, pois segundo Zervoudakis et al. (2002), o crescimento das bactérias celulolíticas é retardado quando o pH é reduzido à níveis inferiores a 6,2 e para Hoover (1986), a atividade celulolítica é inibida em condições que o $\mathrm{pH}$ atinge 5,0 a 5,5. O valor de $\mathrm{pH}$ observado nesse estudo foi próximo ao encontrado por Moraes et al. (2010), quando fornecido suplemento diariamente aos animais, no qual os autores encontraram valores de $\mathrm{pH}$ de 6,68.

\section{Conclusões}

O fornecimento de suplementos múltiplos com níveis crescentes de torta de girassol durante o período da seca resulta em aumento do consumo de matéria seca total. A torta de girassol pode substituir o farelo de soja em até $100 \%$ na formulação dos suplementos sem prejudicar os parâmetros nutricionais dos animais, nesse nível de suplementação.

\section{Referências}

ABDALLA, A. L.; SILVA FILHO, J. C.; GODOI, A. R.; CARMO, C. A.; EDUARDO, J. L. P. Utilização de subprodutos da indústria de biodiesel na alimentação de ruminantes. Revista Brasileira de Zootecnia, Viçosa, MG, v. 37, p. 1806-1817, 2008. Número Especial.

ADAMS, D. C. Effect of time of supplementation on performance, forage intake, and grazing behavior of yearling beef steers grazing Russian wild ryegrass in the fall. Journal of Animal Science, Champaign, v. 61, n. 5, p. 1037-1042, 1985.

BERAN, F. H. B.; SILVA, L. D. F.; RIBEIRO, E. L. A.; CASTRO, V. S.; CORREA, R. A.; KAGUEIAMA, E. O.; ROCHA, M. A. Degradabilidade ruminal "in situ" da matéria seca, matéria orgânica e proteína bruta de alguns suplementos concentrados usados na alimentação de bovinos. Semina Ciências Agrárias, Londrina, v. 26, n. 3, p. 405-418, 2005.

BERCHIELLI, T. T.; PIRES, A. V.; OLIVEIRA, S. G. Nutrição de ruminantes. Jaboticabal: FUNEP, 2006. 583 p.

CABRAL, L. S.; ZERVOUDAKIS, J. T.; COPPEDÊ, C. M.; SOUZA, A. L.; CARAMORI JUNIOR, J. G.; POLIZEL NETO, A.; OLIVEIRA, I. S. Suplementação de bovinos de corte mantidos em pastagem de Panicum maximum cv. Tanzânia-1 no período das águas. Revista Brasileira Saúde Produção Animal, Bahia v. 9, n. 2, p. 293-302, 2008.

CASALI, A. O.; DETMANN, E.; VALADARES FILHO, S. C.; PEREIRA, J. C.; HENRIQUES, L. T.; FREITAS, S. G.; PAULINO, M. F. Influência do tempo de incubação e do tamanho de partículas sobre os teores de compostos indigestíveis em alimentos e fezes bovinas obtidos por procedimento in situ. Revista Brasileira de Zootecnia, Viçosa, MG, v. 37, n. 2, p. 335-342, 2008.

COUTINHO FILHO, J. L. V.; JUSTO, C. L.; PERES, R. M. Desenvolvimento ponderal de bezerras desmamadas em pastejo de Brachiaria decumbens com suplementação protéica e energética. Pesquisa Agropecuária Brasileira, Brasília, v. 40, n. 8, p. 817-823, 2005.

SOUZA, C. C. de. Avaliação econômica parcial de dietas com o farelo e a torta de girassol, na alimentação de vacas leiteiras. 2008. Dissertação (Mestrado em Zootecnia) - Universidade Estadual Paulista, Jaboticabal. 
DelCURTO, T.; COCHRAN, R. C.; CORAH, L. R.; BEHARKA, A. A.; VANZANT, E. S.; HOHNSON, D. E. Supplementation of dormant Tallgrass-Prairie forage: II. Performance and forage utilization characteristics in grazing beef cattle receiving supplements of different protein concentrations. Journal of Animal Science, Champaign, v. 68, n. 2, p. 532-542, 1990.

DETMANN, E.; PAULINO, M. F.; ZERVOUDAKIS, J. T.; VALADARES FILHO, S. C.; EUCLYDES, R. F.; LANA, R. P.; QUEIROZ, D. S. Cromo e indicadores internos na estimação do consumo de novilhos mestiços, suplementados, a pasto. Revista Brasileira de Zootecnia, Viçosa, MG, v. 30, n. 5, p. 1600-1609, 2001.

DOMINGUES, A. R.; SILVA, L. D. F.; RIBEIRO, E. L. A.; CASTRO, V. S.; BARBOSA, M. A. A. F.; MORI, R. M.; VIEIRA, M. T. L.; SILVA, J. A. O. Consumo, parâmetros ruminais e concentração de ureia plasmática em novilhos alimentados com diferentes níveis de torta de girassol em substituição ao farelo de algodão. Semina: Ciências Agrárias, Londrina, v. 31, n. 4, p. 1059-1070, 2010.

GERDES, L.; WERNER, J. C.; COLOZZA, M. T.; POSSENTI, R. A.; SCHAMMASS, E. A. Avaliação de características de valor nutritivo das gramíneas forrageiras Marandu, Setária e Tanzânia nas estações do ano. Revista Brasileira de Zootecnia, Viçosa, MG, v. 29, n. 4, p. 955-963, 2000.

GOES, R. H. T. B.; MANCIO, A. B.; LANA, R. P.; LEÃO, M. I.; ALVES, D. D.; SILVA, A. T. S. Recria de novilhos mestiços em pastos de Brachiaria brizantha, com diferentes níveis de suplementação, na Região Amazônica. Consumo e parâmetros ruminais. Revista Brasileira de Zootecnia, Viçosa, MG, v. 34, n. 5, p. 17301739, 2005.

HALL, M. B. Calculation of non-structural carbohydrate content of feeds that contain non-protein nitrogen. Gainesville: University of Florida, 2000. p. A-25 (Bulletin, 339).

HOOVER, W. H. Chemical factors involved in ruminal fiber digestion. Journal of Dairy Science, Cambridge, v. 69, n. 10, p. 2755-2766, 1986.

LENG, R. A. Factors affecting the utilization of "poorquality" forages by ruminants particularly under tropical conditions. Nutrition Research Review, Cambridge, v. 3, n. 3, p. 277-303, 1990.

McMENIMAN, N. P. Methods of estimating intake of grazing animals. In: REUNIÃO ANUAL DA SOCIEDADE BRASILEIRA DE ZOOTECNIA, 34., Juiz de Fora, 1997. Anais... Juiz de Fora: SBZ, 1997. p. 131-168.
MENDES, A. R.; EZEQUIEL, J. M. B.; GALATI, R. L.; FEITOSA, J. V. Desempenho, parâmetros plasmáticos e características de carcaça de novilhos alimentados com farelo de girassol e diferentes fontes energéticas, em confinamento. Revista Brasileira de Zootecnia, Viçosa, MG, v. 34, n. 2, p. 692-702, 2005.

MORAES, E. H. B. K.; PAULINO, M. F.; VALADARES FILHO, S. C.; MORAES, K. A.; DETMANN, E. SOUZA, M. G. Avaliação nutricional de estratégias de suplementação para bovinos de corte durante a estação da seca. Revista Brasileira de Zootecnia, Viçosa, MG, v. 39, n. 3, p. 608-616, 2010.

NATIONAL RESEARCH COUNCIL - NRC. Nutrients requirements of dairy cattle. 7. ed. Washington: National Academy Press, 2001. 381 p.

OLIVEIRA, M. D. S.; CÁCERES, D. R. Girassol na alimentação de bovinos. Jaboticabal: Funep, 2005. 20 p.

PAULINO, M. F.; FIGUEIREDO, D. M.; MORAES, E. H. B. K.; PORTO, M. O.; SALES, M. F. L.; ACEDO, T. S.; VILLELA, S. D. J.; VALADARES FILHO, S. C. Suplementação de bovinos em pastagens: uma visão sistêmica. In: SIMPÓSIO DE PRODUÇÃO DE GADO DE CORTE, 4., 2004, Viçosa, MG. Anais... Viçosa, MG: SIMCORTE, 2004. p. 93-144.

RENNÓ, L. N.; VALADARES, R. F. D.; VALADARES FILHO, S. C.; LEÃO, M. I.; SILVA, J. F. C.; CECON, P. R.; GOÇALVES, L. C.; DIAS, H. L. C.; LINHARES, R. S. Concentração plasmática de ureia e excreções de ureia e creatinina em novilhos. Revista Brasileira de Zootecnia, Viçosa, MG, v. 29, n. 4, p. 1235-1243, 2000.

SANTOS, E. D. G.; PAULINO, M. P.; QUEIROZ, D. S.; FONSECA, D. M.; VALADARES FILHO, S. C.; LANA, R. P. Avaliação de pastagem diferida de Brachiaria decumbens Stapf. 2. Disponibilidade de forragem e desempenho animal durante a seca. Revista Brasileira de Zootecnia, Viçosa, MG, v. 33, n. 1, p. 214-224, 2004.

SILVA, D. J.; QUEIROZ, A. C. Análise de alimentos: métodos químicos e biológicos. 3. ed. Viçosa: UFV, 2002. $235 \mathrm{p}$.

SNIFFEN, C. J; O'CONNOR, J. D.; VAN SOEST, P. J.; FOX, D. G.; RUSSELL, J. B. A net carbohydrate and protein system for evaluating cattle diets: II. Carbohydrate and protein availability. Journal of Animal Science, Cambridge, v. 70, n. 12, p. 3562-3577, 1992.

VALADARES FILHO, S. C.; PAULINO, P. V. R.; MAGALHÃES, K. A. Exigências nutricionais de zebuinos e tabelas de composição de alimentos (BRCORTE). Visconde do Rio Branco: Suprema Gráfica Ltda, 2006. v. 1, 142 p. 
VALADARES, R. F. D.; BRODERICK, G. A.; VALADARES FILHO, S. C.; CLAYTON, M. K. Effect of replacing alfalfa silage with high moisture corn on ruminal protein synthesis estimated from excretion of total purine derivatives. Journal of Dairy Science, Cambridge, v. 82, n. 11, p. 2686-2696, 1999.
VAN SOEST, P. J.; ROBERTSON, J. B.; LEWIS, B. A. Symposium: carboydrate metodology, metabolism, and nutritional implications in dairy cattle. Journal Dairy Science, Cambridge, v. 74, n. 10, p. 3583-3597, 1991.

ZERVOUDAKIS, J. T.; PAULINO, M. F.; DETMANN, E.; VALADARES FILHO, S. C.; LANA, R. P.; CECON, P. R. Desempenho de novilhas mestiças e parâmetros ruminais em novilhos, suplementados durante o período das águas. Revista Brasileira de Zootecnia, Viçosa, MG, v. 31, n. 2, p. 1050-1058, 2002. 